\title{
ONLINE APPENDIX:
}

\section{Individual Identity and Organizational Identification: Evidence from a Field Experiment}

By Maria Guadalupe, Zoe Kinias and Florian Schloderer

\begin{tabular}{|c|c|c|}
\hline & (1) & (2) \\
\hline & Org Ident & Org Ident \\
\hline \multirow[t]{2}{*}{ Female } & -0.194 & -0.299 \\
\hline & $(0.127)$ & $(0.117)$ \\
\hline \multirow[t]{2}{*}{ Manager } & 0.437 & 0.335 \\
\hline & $(0.160)$ & $(0.146)$ \\
\hline \multirow[t]{2}{*}{ Age } & 0.0301 & 0.00250 \\
\hline & $(0.0801)$ & $(0.0726)$ \\
\hline \multirow[t]{2}{*}{ Age Squared } & -0.000315 & -0.000132 \\
\hline & $(0.00108)$ & $(0.000982)$ \\
\hline \multirow[t]{2}{*}{ HQ } & -0.0172 & -0.0254 \\
\hline & $(0.156)$ & $(0.142)$ \\
\hline \multirow[t]{2}{*}{ Indiv Ident --Eudaimonic } & & 0.231 \\
\hline & & $(0.0776)$ \\
\hline \multirow[t]{2}{*}{ Life Satisfaction } & & 0.280 \\
\hline & & $(0.0700)$ \\
\hline \multirow[t]{2}{*}{ No Stress } & & 0.106 \\
\hline & & $(0.0894)$ \\
\hline Region of origin dummies & yes & yes \\
\hline Observations & 351 & 347 \\
\hline R-squared & 0.087 & 0.273 \\
\hline
\end{tabular}




\begin{tabular}{lll}
\multicolumn{3}{c}{ TABLE A2: FACTOR ANALYSIS OF II AND OI } \\
\hline & Factor 1 & Factor 2 \\
& ALIGNED & MISALIGNED \\
Eigenvalue: & 5.04 & 1.96 \\
\% Variance Explained & $73 \%$ & $28 \%$ \\
\hline \hline
\end{tabular}

$\begin{array}{lcc}\text { Factor Loadings } & \\ \text { Indiv Ident- Eudaimonic: } & & \\ \text { centered core beliefs } & 0.56 & 0.41 \\ \text { know who I am } & 0.62 & 0.49 \\ \text { know my purpose } & 0.65 & 0.51 \\ \text { can be my who I am } & 0.64 & 0.52 \\ \text { feel authentic } & 0.64 & 0.5 \\ \text { Org Identif: } & & \\ \text { work accomplishemnt } & 0.73 & -0.28 \\ \text { stay at XXX } & 0.66 & -0.38 \\ \text { sense of belonging } & 0.73 & -0.4 \\ \text { achieve purpose } & 0.74 & -0.41 \\ \text { add value } & 0.76 & -0.31 \\ \text { Empowered } & 0.69 & -0.34\end{array}$

